\title{
Serum thyroglobulin concentrations and whole-body radioiodine scan in follow-up of differentiated thyroid cancer after thyroid ablation
}

\section{Summary and conclusions}

Measurement of serum thyroglobulin ( $\mathrm{Tg}$ ) concentrations and whole-body radioiodine scan were performed simultaneously during follow-up of 32 patients with differentiated thyroid cancer who had undergone thyroid ablation by operation and radioiodine. Almost all patients in whom serum $\mathrm{Tg}$ was undetectable had normal scans. Concentrations exceeding $50 \mathrm{ng} / \mathrm{ml}$ were invariably associated with residual or metastatic tumour uptake in the scan. Out of 21 observations of detectable values below $50 \mathrm{ng} / \mathrm{ml}, 14$ were in patients whose scans showed subclinical or sub-radiological tumour uptake and seven in patients with normal scans.

The sensitivity of serum $\mathrm{Tg}$ as a tumour marker compared favourably to that of the whole-body scan. A scan is unnecessary when serum $\mathrm{Tg}$ is undetectable, but in patients with detectable serum $\mathbf{T g}$ concentrations, particularly if these are below $50 \mathrm{ng} / \mathrm{ml}$, a scan is important to assess and localise tumour uptake of iodine before advising treatment with iodine-131.

\section{Introduction}

Differentiated thyroid cancers, like normal thyroid, produce thyroglobulin $(\mathrm{Tg})$ that may be measured in peripheral blood by sensitive radioimmunoassay techniques. ${ }^{12}$ High circulating $\mathrm{Tg}$ concentrations, however, may also be found in various benign thyroid diseases, ${ }^{13}$ and small thyroid tumours may not raise the value above normal. ${ }^{4}$ In patients with known papillary or follicular thyroid carcinomas who have undergone operation serum $\mathrm{Tg}$ concentrations fall to normal or undetectable values in the absence of residual tumour but remain abnormally raised in the presence of known metastases or recurrence. ${ }^{235}$ Hence serum $\mathrm{Tg}$ has been proposed as a tumour marker in the follow-up of patients with differentiated thyroid cancer.

To assess the sensitivity of serum $\mathrm{Tg}$ measurement as a tumour marker after thyroid ablation we have compared it with whole-body radioiodine scan, which is currently the most sensitive technique for detecting and localising functioning thyroid tumour. ${ }^{\circ}$

\footnotetext{
Department of Nuclear Medicine and Endocrinology, Guy's Hospital, London SE1 9RT

SERGE C NG TANG FUI, BSC, MRCP, research fellow and honorary lecturer in medicine

MICHAEL N MAISEY, MD, FRCP, consultant physician and head of nuclear medicine department

Department of Medicine, Queen Elizabeth Hospital, Birmingham B15 2TH

RAYMOND HOFFENBERG, MD, FRCP, professor of medicine

ELIZABETH G BLACK, BSC, research fellow
}

\section{Patients and methods}

We studied 32 patients who had undergone routine partial or total thyroidectomy for papillary or follicular thyroid carcinoma. A thyroid scan with ${ }^{99} \mathrm{mTc}$, ${ }^{131} \mathrm{I}$, or ${ }^{123} \mathrm{I}$ was carried out during the first postoperative week, and $80 \mathrm{mCi}$ iodine-131 was given to every patient with neck uptake corresponding to residual normal thyroid tissue to complete its ablation. Without any intervening thyroid replacement therapy for six weeks after ablation, a whole-body scan with a dual 5 -in $(13-\mathrm{cm})$ sodium iodide rectilinear scanner (Ohio Nuclear) was performed on every patient 72 hours after a dose of $15 \mathrm{mCi}$ iodine$131^{6}$ to assess residual or metastatic tumour uptake. If any was seen the patient was immediately admitted and given $150 \mathrm{mCi}$ iodine- 131 . The whole-body scan and further treatment with iodine-131 if necessary were repeated at six-month intervals until uptake was no longer seen. The scan was then carried out yearly until it remained clear for two consecutive years. All patients were maintained with suppressive doses of thyroxine, $0 \cdot 2-0.3 \mathrm{mg}$ daily, except for one month before each scan and for four days after each therapeutic dose of iodine- 131 .

Blood for measuring serum $\mathrm{Tg}$, thyroxine (T4), and thyroidstimulating hormone (TSH) concentrations was taken immediately before giving the scanning dose of iodine. Serum T4 and TSH were measured by routine radioimmunoassay techniques. Serum $\mathrm{Tg}$ was measured by a slight modification of the method of Van Herle et al, using $100 \mu \mathrm{l}$ serum, incubation at room temperature for 48 hours, and precipitation of antigen-antibody complexes with antirabbit immunoglobulin. The limit of detection of serum $\mathrm{Tg}$ in the assay was $1 \mathrm{ng} / \mathrm{ml}$, and the concentration in normal people ranged from below 1 to $43 \mathrm{ng} / \mathrm{ml}$.

\section{Results}

Of the 32 patients, 21 had papillary and 11 follicular thyroid carcinomas. Although all had been scanned regularly from the time of diagnosis as outlined above, they were at different stages of followup, ranging from six weeks to five years after thyroid ablation, when serum $\mathrm{Tg}$ was first measured. The results of 51 serum $\mathrm{Tg}$ measurements and whole-body scans were available for analysis (fig 1), some patients having had repeat paired investigations after radioiodine treatment or after suppressive doses of thyroxine only.

The results may be divided into three groups. (1) Nine patients had undetectable serum $\mathrm{Tg}$ when first tested, of whom none had clinical or scintigraphic evidence of functioning residual tumour. The results were unchanged in two out of three patients who had both investigations repeated after a year; the third patient, however, had a slight recurrence of iodine uptake in the neck despite undetectable serum $\mathrm{Tg}$ but this was not thought to warrant radioiodine treatment. (2) Seventeen patients with clear evidence of residual or metastatic tumour uptake in the scan had serum $\mathrm{Tg}$ concentrations ranging from 1 to over $500 \mathrm{ng} / \mathrm{ml}$. There was good correlation between the extent of tumour uptake in the scan and the serum $\mathrm{Tg}$ value. The highest $\mathrm{Tg}$ values were found in seven patienis with iodine uptake in widespread lung metastases or in palpable tumour masses in the neck. In patients with serum $\mathrm{Tg}$ concentrations below $50 \mathrm{ng} / \mathrm{ml}$ and an abnormal scan residual or metastatic tumour was not detectable clinically or radiologically. Response to one or more therapeutic doses of iodine-131 in patients with residual or metastatic tumour was in general mirrored by improved tumour uptake in the scan and a fall in serum $\mathrm{Tg}$ values (fig 2 ). In one patient, however, the serum $\mathrm{Tg}$ concentration fell from 125 to $43 \mathrm{ng} / \mathrm{ml}$ six months after radioiodine treatment but the post-treatment scan was normal. (3) Six patients whose whole-body scan was normal had serum $\mathrm{Tg}$ concentrations of $3 \cdot 7-38 \cdot 5 \mathrm{ng} / \mathrm{ml}$, but $\mathrm{Tg}$ became undetectable after a year in two of them while the scan remained normal. 
One case was particularly interesting and is described below.

The patient, a 26-year-old man, was found to have an inoperable follicular thyroid carcinoma. Six weeks after a dose of $80 \mathrm{mCi}$ iodine-131 to ablate normal thyroid tissue, and without intervening thyroxine replacement therapy, tumour uptake of iodine was seen in the neck without any functioning metastases. Two treatment doses of $150 \mathrm{mCi}$ iodine- 131 at four-month intervals produced some improvement in the size and uptake of the local tumour with a corresponding fall in the serum $\mathrm{Tg}$ concentration from over $500 \mathrm{ng} / \mathrm{ml}$ to $220 \mathrm{ng} / \mathrm{ml}$. Operation was then advised, and the rest of the tumour was completely removed with no residual uptake seen in the postoperative scan. Serum $\mathrm{Tg}$ was measured within one hour after

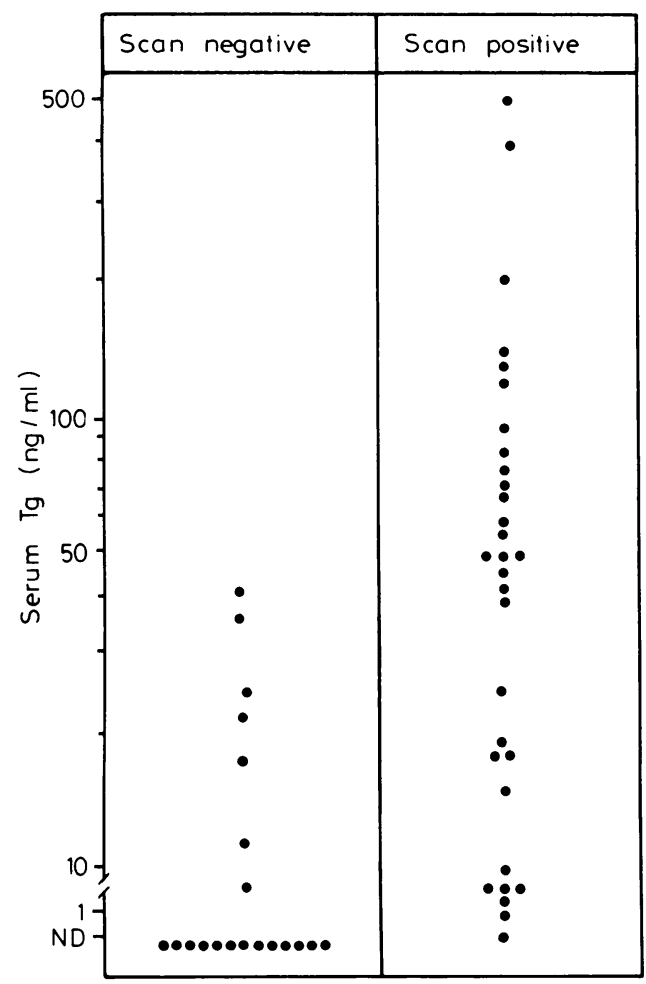

FIG 1 -Serum $\mathrm{Tg}$ concentrations (log scale) and results of whole-body radioiodine scan for residual tumour uptake after total thyroid ablation. $\mathrm{ND}=$ Not detectable.

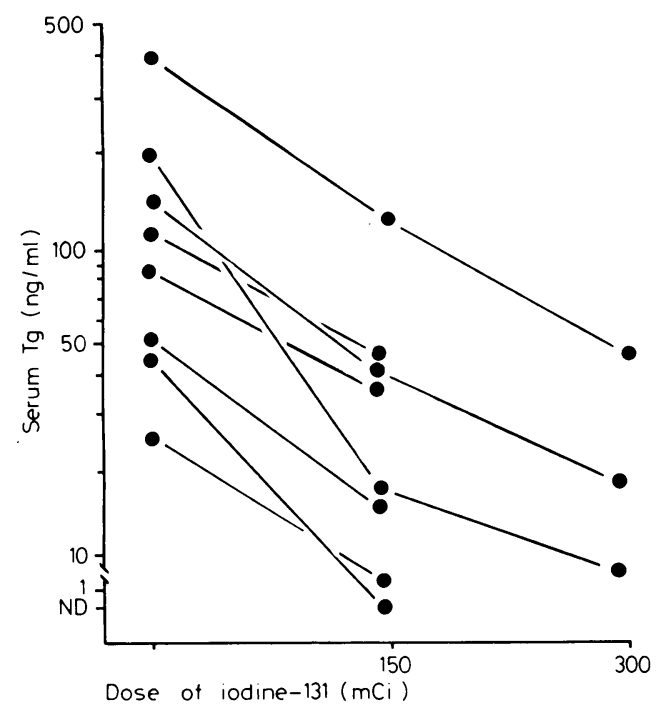

FIG 2-Serum $\mathrm{Tg}$ concentrations (log scale) before and after treatment with iodine-131 in eight patients with residual or metastatic tumour after thyroid ablation. Concentrations were measured six months after each therapeutic dose. ND $=$ Not detectable. tumour excision and at frequent intervals over the next 11 days. Fig 3 plots the $\mathrm{Tg}$ concentrations, which suggest that the biological half life of $\mathrm{Tg}$ is about 65 hours.

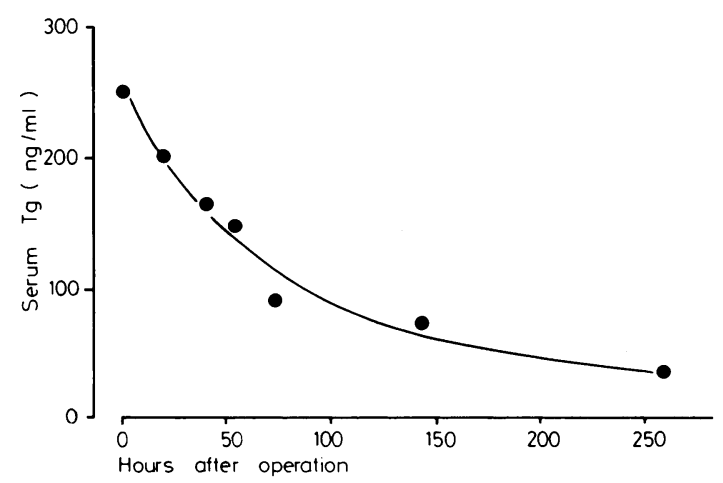

FIG 3-Fall in serum $\mathrm{Tg}$ concentrations in one patient after complete excision of residual thyroid tumour after treatment with iodine-131.

\section{Discussion}

Patients subjected to total thyroid ablation for differentiated thyroid carcinoma should have undetectable circulating $\mathrm{Tg}$ unless residual or recurrent functioning tumour is present. In our study serum $\mathrm{Tg}$ matched the whole-body radioiodine scan as a marker for persistent tumour in $43\left(84_{\%}^{\circ}\right)$ of the 51 paired investigations. In 13 of these serum $\mathrm{Tg}$ was undetectable when the scan was normal; in 30 others serum $\mathrm{Tg}$ concentrations of 1 to over $500 \mathrm{ng} / \mathrm{ml}$ were found when the scan showed residual or metastatic tumour uptake. On seven occasions, however, serum $\mathrm{Tg}$ concentrations of $3 \cdot 7-43.0 \mathrm{ng} / \mathrm{ml}$ were detectable despite a normal scan. Differentiated thyroid tumour may fail to concentrate iodine because of insufficient release of $\mathrm{TSH}$, but in all seven patients serum TSH concentrations of $40 \mathrm{mU}$ or more $/ 1$ were recorded at the time of scanning. Possibly some tumours leak $\mathrm{Tg}$ into the circulation without demonstrable uptake of radioiodine. The converse was apparently found in only one patient, in whom serum $\mathrm{Tg}$ was undetectable despite a scan showing slight iodine uptake in the neck. Discordance of iodide trapping and $\mathrm{Tg}$ secretion may thus be a feature of some thyroid tumours.

Since serum $\mathrm{Tg}$ measurement clearly compares favourably to whole-body radioiodine scan in assessing functioning tumour after initial treatment, the possibility arises that the simpler measurement of serum $\mathrm{Tg}$ concentration could replace the time-consuming and expensive scan, which can be performed only in specially equipped nuclear medicine departments. In our series the presence or absence of functioning tumour as determined by scanning was correctly assessed from the serum $\mathrm{Tg}$ concentration in $84 \%$ of cases. If we consider patients with undetectable serum $\mathrm{Tg}$ the correlation with a normal scan was nearly $100^{\circ}$, and in such patients a whole-body scan is unnecessary. Measurement of the serum $\mathrm{Tg}$ concentration would thus be particularly useful in the long-term follow-up of patients.with no clinical evidence of disease. We also found that when the serum $\mathrm{Tg}$ concentration exceeded $50 \mathrm{ng} / \mathrm{ml}$ the scan was invariably positive for tumour uptake. A scan is again unnecessary in such cases unless the site and activity of tumour need to be localised for possible treatment with iodine-131.

Disparity between the two methods arose chiefly when detectable serum $\mathrm{Tg}$ concentrations were normal-that is, below $50 \mathrm{ng} / \mathrm{ml}$. Out of 21 observations in this group, the scan was abnormal in $14\left(67^{\circ}\right)$ but normal in $7\left(33_{\%}^{\circ}\right)$. A scan is probably necessary in such cases to assess iodine uptake before advising treatment with iodine-131.

We measured serum $\mathrm{Tg}$ concentrations at the time of the whole-body scan-that is, after four weeks without thyroxine to ensure that serum $\mathrm{TSH}$ values were high enough to induce tumour uptake. ${ }^{8}$ Withdrawal of treatment usually results in 
unpleasant symptoms of hypothyroidism. Differentiated thyroid tumours may continue to secrete $\mathrm{Tg}$ despite continued suppressive treatment with thyroxine; the finding of high serum $\mathrm{Tg}$ values in such patients may obviate the need to stop thyroxine before carrying out the investigation. This aspect is being studied further.

Dr Serge C Ng Tang Fui is supported by a research grant from the Guy's Hospital Special Trustees.

Requests for reprints should be addressed to: Dr M N Maisey, Department of Nuclear Medicine and Endocrinology, Guy's Hospital, London SE1 9RT.

\section{References}

1 Van Herle, A J, et al, fournal of Clinical Investigation, 1973, 52, 1320.

2 Van Herle, A J, and Uller, R P, fournal of Clinical Investigation, 1975, $56,272$.

${ }^{3}$ Shlossberg, A H, Jacobson, J C, and Ibbertson, H K, Clinical Endocrinology, 1979, 10, 17.

4 Schneider, A B, et al, Annals of Internal Medicine, 1977, 86, 29.

${ }^{5}$ Lo Gerfo, P, et al, Lancet, 1977, 1, 881.

${ }^{6}$ Maisey, M N, and Ng Tang Fui, S C, in Thyroid Cancer, ed W Duncan. Berlin, Springer-Verlag. In press.

7 Pochin, E E, Clinical Radiology, 1967, 18, 113.

${ }^{8}$ Edmonds, C J, et al, British Fournal of Radiology, 1977, 50, 799.

(Accepted 28 fune 1979)

\title{
Randomised trial comparing buprenorphine and diamorphine for chest pain in suspected myocardial infarction
}

\author{
M J HAYES, A R FRASER, J R HAMPTON
}

British Medical fournal, 1979, 2, 300-302

\section{Summary and conclusions}

Buprenorphine, a new powerful analgesic agent, was used to treat chest pain in patients with suspected myocardial infarction. Initial studies showed no significant changes in systemic or pulmonary artery blood pressure or in heart rate after intravenous buprenorphine. Sublingual buprenorphine also appeared effective in relieving pain, but its onset of action was considerably delayed compared with the intravenous route. A randomised double-blind controlled trial of equivalent doses of buprenorphine and diamorphine showed no significant difference between the drugs in terms of pain relief and duration of action. The occurrence of nausea, vomiting, and other side effects was similar in the two groups. The onset of action of buprenorphine was slightly but significantly slower than that of diamorphine.

Since buprenorphine seems to be comparable with diamorphine in action and is not a controlled drug, it may prove useful in both general and hospital practice.

\section{Introduction}

In many respects diamorphine is an ideal drug for relieving the pain of myocardial infarction. It is a powerful analgesic, its effect is rapid, and it is free of adverse haemodynamic side effects. Unfortunately it is addictive and therefore unpopular, particularly with general practitioners. Attempts to find equally powerful but non-addictive analgesic drugs have been unsuccessful; in particular, pentazocine was found to cause pulmonary and systemic vasoconstriction and was therefore unsuitable for patients with heart disease. ${ }^{1}$

Department of Medicine, University Hospital, Nottingham

M J HAYES, DM, MRCP, senior medical registrar

A R FRASER, MB, MRCP, senior house officer

J R HAMPTON, DM, FRCP, consultant physician and reader in medicine
Buprenorphine (Temgesic, Reckitt \& Colman) is a synthetic compound derived from thebaine, which has been found effective in relieving postoperative pain. ${ }^{2}$ It has recently been released as a non-controlled drug. We describe here a study on the haemodynamic effects of buprenorphine in patients with myocardial infarction, a comparison of the action of intravenous and sublingual routes of administration, and also a double-blind controlled study comparing intravenous buprenorphine and diamorphine in the relief of chest pain due to suspected myocardial infarction.

\section{Patients and methods}

Three studies were performed.

Study 1-Haemodynamic studies were performed on an initial 10 patients with myocardial infarction proved on electrocardiography (ECG). All had received diamorphine previously but then required further analgesia for recurrent pain. The pulmonary artery pressure was recorded continuously before and after an intravenous injection of $0.3 \mathrm{mg}$ buprenorphine, by means of a $3 \mathrm{~F}$ gauge polyethylene catheter inserted percutaneously via an antecubital vein. Cuff measurements of the systemic blood pressure were made at defined intervals. The ECG was monitored continuously and measurements of heart rate obtained from the ECG.

Study 2-Forty-three patients who required analgesia in the coronary care unit (CCU) were given either injections of intravenous buprenorphine or sublingual tablets. Eighteen received a total of 20 tablets of sublingual buprenorphine $0.4 \mathrm{mg}$, and 25 received a total of 40 injections of intravenous buprenorphine $0.3 \mathrm{mg}$ as and when they needed analgesia for chest pain. In this group only systemic blood pressure and heart rate were measured and the ECGs were continuously monitored. The degree of pain relief and more particularly the time of onset of pain relief was assessed subjectively by the medical and nursing staff.

Study 3-One hundred and twenty patients who were admitted to the CCU with chest pain due to suspected myocardial infarction and who required analgesia were randomly allocated in a double-blind fashion to receive either buprenorphine $0.3 \mathrm{mg}$ intravenously or diamorphine $5 \mathrm{mg}$ intravenously. There were no medical contraindications for inclusion in this trial. Patients were randomised in blocks of six, the trial ampoules being prepared and issued by the General Hospital pharmacy daily because of the instability of diamorphine when in solution. After entry into the trial records were kept of the time, dose, and frequency of subsequent analgesic adminis-

\section{更}

